[0212-7199 (2005) 22: 5; pp 238-240] ANALES DE MEDICINA INTERNA Copyright (C) 2005 ARAN EDICIONES, S.L.

AN. MED. INTERNA (Madrid) Vol. 22, N. ${ }^{\circ}$ 5, pp. 238-240, 2005

\title{
Quilotórax tuberculoso: caso clínico y revisión de la literatura
}

\author{
M. SAUMOY, M. MIRÓN', C. OLTRA, F. VIDAL, C. RICHART \\ Servicio de Medicina Interna. ${ }^{1}$ Unidad de Hospitalización a Domicilio. Hospital \\ Universitari Joan XXIII. Universitat Rovira i Virgili. Tarragona
}

\begin{abstract}
TUBERCULOUS CHYLOTHORAX: CASE REPORT AND REVIEW OF THE LITERATURE
\end{abstract}

\section{RESUMEN}

El quilotórax es una manifestación infrecuente de la enfermadad tuberculosa. En la literatura se han descrito casos anecdóticos de quilotórax producido por Mycobacterium tuberculosis. Describimos un caso clínico de quilotórax de etiología tuberculosa y revisamos los casos publicados en la literatura médica. En ningún caso el diagnóstico etiológico se realizó mediante la aplicación de la reacción en cadena de polimerasa (PCR) en el líquido de quilotórax. Esta técnica ha demostrado una alta sensibilidad y especificidad cuando se aplica a distintos especímenes; por este motivo, el uso sistemático de esta técnica poco agresiva podría ser de gran utilidad para establecer el diagnóstico precoz del quilotórax tuberculoso especialmente en aquellos casos sin evidencia radiológica de afectación pulmonar.

PALABRAS CLAVE: Quilotórax. Tuberculosis. Reacción en cadena de la polimerasa.

\begin{abstract}
Chylothorax is an inusual manifestation of tuberculous disease. Anecdotal cases of chylothorax due to Mycobacterium Tuberculosis have been reported in the literature. We describe a case of tuberculous chylothorax and review the previously published cases. None of these cases was diagnosed by the aplication of polymerase chain reaction in pleural effusion. This test applaied to different specimenes has shown a high especificity and sensitivity; for this reason, the routin use of this test, on pleural effusion, could be very useful, quick, and few agressive in the diagnosis of tuberculous chylothorax, especially when chest X-ray is normal.
\end{abstract}

KEY WORDS: Chylothorax. Tuberculosis. Polymerase chain reaction.

Saumoy M, Mirón M, Oltra C, Vidal F, Richart C. Quilotórax tuberculoso: caso clínico y revisión de la literatura. An Med Interna (Madrid) 2005; $22: 238-240$

\section{INTRODUCCIÓN}

El quilotórax es un derrame pleural causado por el acúmulo de quilo en el espacio pleural como consecuencia del daño o bloqueo del conducto torácico. Los traumatismos constituyen la etiología más frecuente de quilotórax $(1,2)$. En la literatura se han descrito casos anecdóticos producidos por $\mathrm{Myco}$ bacterium tuberculosis (3-7).

Presentamos el caso de un paciente afecto de quilotórax tuberculoso cuyo diagnóstico de confirmación se realizó mediante la identificación del bacilo de Koch por la técnica de la reacción en cadena de la polimerasa (PCR) en una muestra de tejido pulmonar. Revisamos los casos de quilotórax tuberculoso publicados en la literatura (medline 1966- abril 2004; palabras clave: chylothorax. polymerase chain reaction, tuberculosis)

\section{CASO APORTADO}

Varón de 81 años, con antecedentes de fibrilación auricular crónica, que acudió a nuestro hospital por cuadro de dísnea progresiva de 2 meses de evolución, acompañada de astenia y pérdida de peso no cuantificada. El paciente estaba afebril, objetivándose semiología de derrame pleural derecho. La radiografía de tórax confirmó el derrame pleural y un ensanchamiento mediastínico sin afectación de parénquima pulmonar. El análisis de sangre fue normal. La toracocentesis mostró un líquido espeso de aspecto lechoso con 1400 leucocitos $/ \mathrm{mm}^{3}$ con un $10 \%$ de neutrófilos y $90 \%$ de linfocitos, proteinas $49 \mathrm{gr} / \mathrm{L}$ (cociente pleuroplasmático: 0'66), LDH $262 \mathrm{U} / \mathrm{L}$ (cociente pleuroplasmático: 0,75), glucosa 10,2 mmol/L, ADA 16 $\mathrm{U} / \mathrm{L}$, colesterol $1,75 \mathrm{mmol} / \mathrm{L}$ y triglicéridos $12,8 \mathrm{mmol} / \mathrm{L}$. La citología y el cultivo convencional fueron negativos. La intradermoreacción de Mantoux fue negativa.

La fibrobroncoscopia no mostró lesiones endobronquiales. La tinción de Ziehl-Neelsen y el cultivo en medio de Löwenstein-Jensen

Trabajo aceptado: 13 de diciembre de 2004

Correspondencia: Manuel Mirón Rubio. Servicio de Medicina Interna. Hospital Universitari Joan XXIII. C/ Doctor Mallafré Guash, 4. 43007 Tarragona. e-mail: mmiron70@hjxxiii.scs.es 
del lavado broncoalveolar fueron negativos. Una TC toracoabdominal mostró múltiples masas adenopáticas en el mediastino y derrame pleural bilateral de predominio derecho. Se realizó una punción-aspiración con aguja fina guiada por TC de la masa mediastínica, sin poderse recoger muestra de tejido adenopático. Se realizó entonces, toracoscopia con biopsia pleural y pulmonar, y colocación de un tubo de drenaje pleural. La anatomia patológica mostró lesiones granulomatosas crónicas compatibles con tuberculosis tanto en pleura como en pulmón. La PCR para Mycobacterium tuberculosis fue positiva en la biopsia pulmonar y negativa en pleura. Se inició tratamiento con Isoniazida $300 \mathrm{mg} /$ día, Rifampicina $600 \mathrm{mg}$ /día y Pirazinamida 1250 $\mathrm{mg}$ /día. Pese al tratamiento instaurado, el paciente presentó un empeoramiento clínico e insuficiencia respiratoria, siendo exitus. Se realizó la necropsia que informó de quilotórax bilateral, linfadenitis crónica granulomatosa caseificante compatible con tuberculosis de ganglios linfáticos mediastínicos y diseminación miliar pleuropulmonar bilateral, hepática, suprarrenal izquierda y renal.

\section{DISCUSIÓN}

El quilotórax está causado por una obstrucción o laceración del conducto torácico, que produce la salida de quilo al espacio pleural. Puede presentarse de forma unilateral o bilateral dependiendo del nivel en el que se produzca la lesión. La causa más frecuente de quilotórax es la traumática, ya sea accidental o iatrogénica. Entre las causas no traumáticas, las neoplasias, y entre ellas el linfoma son la causa más común $(1,2)$. La tuberculosis es una causa excepcional de quilotórax (3-8), cuyo origen se debe habitualmente a la compresión del conducto torácico por adenopatías mediastínicas $(3,6)$.

El diagnóstico del quilotórax tuberculoso se realiza mediante el análisis del líquido pleural y la identificación de la micobacteria. El líquido quiloso presenta un aspecto característicamente lechoso debido a su alto contenido en triglicéridos. Un nivel de triglicéridos mayor a 1,24 mmol/L confirma el diagnóstico de quilotórax. Cuando los niveles de triglicéridos estan entre 0,56 $\mathrm{mmol} / \mathrm{L}$ i 1,24 mmol/L, la presencia de quilomicrones en la electroforesis lipídica establece el diagnóstico de quilotórax $(1,2)$.

Las técnicas de imagen suelen mostrar, además del derrame pleural, infiltrados pulmonares característicos de la afectación pulmonar por Mycobacterium tuberculosis y ensanchamiento mediastínico por adenopatías (Tabla I). Sin embargo, la ausencia de afectación pulmonar radiológica no descarta el diagnóstico, como ocurrió en nuestro caso. De la misma manera, el caso presentado por Anton et al. la TC torácica no objetivó adenopatías mediastínicas, sugeriendo los autores que el conducto torácico y/o los grandes canales linfáticos podrían estar afectados directamente por M. tuberculosis en ausencia de patología toracoabdominal demostrable (4).

TABLA I

CASOS DE QUILOTÓRAX TUBERCULOSOS PUBLICADOS EN LA LITERATURA

\begin{tabular}{|c|c|c|c|c|c|c|}
\hline \multirow{2}{*}{$\begin{array}{l}\text { Edad/Sexo/ } \\
\text { Ref. }\end{array}$} & \multirow[t]{2}{*}{ Rx de tórax/TC torácico } & \multicolumn{4}{|c|}{ Líquido pleural } & \multirow[t]{2}{*}{ Otras técnicas diagnósticas } \\
\hline & & $\begin{array}{c}T G \\
(m m o l / L)\end{array}$ & $\begin{array}{l}\text { BAAR } \\
(U / L)\end{array}$ & Low & $P C R$ & \\
\hline $\begin{array}{l}40 \\
V \\
3\end{array}$ & $\begin{array}{l}\text { Infiltrados apicales bilaterales } \\
\text { cavitados, derrame pleural } \\
\text { izquierdo, adenopatías } \\
\text { mediastínicas }\end{array}$ & $0,6 \mathrm{QM}(+)$ & $(-)$ & ND & ND & Tinción de Zielh-Nielsen de esputo (+) \\
\hline $\begin{array}{l}82 \\
M \\
4\end{array}$ & Derrame pleural derecho & 37,2 & $(-)$ & $(+)$ & ND & \\
\hline $\begin{array}{l}49 \\
M \\
5\end{array}$ & $\begin{array}{l}\text { Lesiones calcificadas en ambos } \\
\text { campos pulmonares, opacidad } \\
\text { no homogénea en lóbulo } \\
\text { superior derecho y derrame } \\
\text { pleural derecho }\end{array}$ & 6,7 & ND & $(-)$ & ND & $\begin{array}{l}\text { Biopsia pleural y pulmonar: } \\
\text { granulomas caseificados }\end{array}$ \\
\hline $\begin{array}{l}29 \\
V \\
6\end{array}$ & $\begin{array}{l}\text { Infiltrados pulmonares bilaterales, } \\
\text { derrame pleural bilateral, } \\
\text { adenopatías mediastínicas }\end{array}$ & 25,5 & ND & ND & ND & $\begin{array}{l}\text { PCR (+) en biopsia pleural. } \\
\text { Tinción de Zielh-Nielsen esputo (+) }\end{array}$ \\
\hline $\begin{array}{l}68 \\
M \\
7\end{array}$ & $\begin{array}{l}\text { Patrón intersticial bilateral, } \\
\text { derrame pleural bilateral, } \\
\text { adenopatías mediastínicas }\end{array}$ & 11,5 & $(-)$ & ND & ND & Low (+) en aspirado broncoalveolar \\
\hline $\begin{array}{l}81 \\
V\end{array}$ & $\begin{array}{l}\text { Masa adenopática mediastínica, } \\
\text { derrame pleural bilateral más } \\
\text { importante en lado derecho }\end{array}$ & 12,8 & ND & ND & ND & $\begin{array}{l}\text { Biopsia pulmonar: inflamación } \\
\text { crónica granulomatosa. PCR (+) }\end{array}$ \\
\hline
\end{tabular}

Rx: radiografía; TC: tomografía computerizada; PPD: derivado proteico purificado; TG: triglicérido; QM: quilomicrones; ADA: adenosin deaminasa; Low: medio de cultivo de Löwenstein-Jensen; PCR: reacción en cadena de la polimerasa; V: varon; M: mujer; (+): positivo; (-): negativo; ND: no disponible. 
De los casos comunicados el diagnóstico etiológico se ha realizado mediante la identificación del microorganismo en diferentes muestras (Tabla I). En el líquido pleural, la tinción de Zielh-Nielsen ha sido negativa en los 3 casos en que se ha realizado y el cultivo en medio de Löwenstein-Jensen ha permitido el diagnóstico en 1 caso. Dichas técnicas también han demostrado una baja sensibilidad en la tuberculosis pleural (8).

El caso que presentamos es el segundo descrito en la literatura en que la PCR para $M$. tuberculosis permite establecer el diagnóstico etiológico. Cuando la PCR se aplica sobre diferentes especímenes clínicos presenta una especificidad del 70$95 \%$ y una sensibilidad cercana al $100 \%(9,10)$. Sin embargo, en ninguno de los casos comunicados, incluido el nuestro, esta técnica ha sido aplicada directamente en el líquido de quilotórax, por lo que se desconoce su utilidad para el diagnóstico del quilotórax tuberculoso. La alta rentabilidad diagnóstica demostrada en el derrame de la tuberculosis pleural $(10,11)$, junto a la escasa agresividad de la técnica y la rapidez diagnóstica hacen recomendable, desde nuestro punto de vista, la aplicación rutinaria de esta técnica ante un quilotórax no traumático.

El diagnóstico diferencial del quilotórax incluye aquellas patologías cuyos líquidos pleurales presentan un aspecto macroscópico lechoso, como el empiema o el pseudoquilotórax. El análisis bioquímico permite diferenciar dichos líqui- dos. El pseudoquilotórax es un derrame pleural crónico con un alto contenido en colesterol, y es la tuberculosis la etiología más frecuente (12).

El tratamiento del quilotórax tuberculoso incluye la terapia farmacológica antituberculosa y la colocación de un tubo torácico para su completo drenaje. En algunos casos es necesario la ligadura quirúrgica del conducto torácico (13). Los casos hallados en la literatura fueron tratados médicamente y con tubo de drenaje con buena evolución clínica; en un caso fue necesario la ligadura quirúrgica del conducto torácico (6). Nuestro paciente fue el único que presentó una mala evolución clínica con fallo multiorgánico producido por la diseminación de la enfermadad tuberculosa, confirmada en la autopsia.

En conclusión, ante el diagnóstico de quilotórax se debe investigar la etiología tuberculosa cuando no existe antecedente de traumatismo o cirugía torácica, a pesar de la ausencia de afectación pulmonar y/o mediastínica en las pruebas de imagen. En estos casos, la aplicación de las técnicas microbiológicas habituales para la identificación del bacilo de Koch puede retrasar el diagnóstico o resultar negativas, lo que generalmente obliga a la práctica de pruebas más agresivas como la biopsia pleural o pulmonar. La PCR aplicada al líquido de quilotorax tuberculoso puede permitir un diagnóstico etiológico precoz y mínimamente invasivo. Es necesario, sin embargo, establecer la rentabilidad diagnóstica de esta prueba mediante su uso sistemático.

\section{Bibliografía}

1. Teba L, Dedhia H, Bowen R, Alexander JC. Chilotorax review. Crit Care Med 1985; 13: 49-52.

2. Hillerdal G. Chylothorax and pseudochilothorax. Eur Respir J 1997; 10: 1157-62.

3. Haro M, Ruiz J, Álvarez J, Gallego M. Quilotórax tuberculoso. Enferm Infecc Microbiol Clin 1994; 12: 57-8.

4. Antón PA, Rubio J, Casan P, Franquet T. Chylothorax due to Mycobacterium tuberculosis. Thorax 1995; 50: 1019.

5. Vennera M, Moreno R, Cot J, Marin A, Sanchez-Lloret J, Picado C, Agusti-Vidal A. Chylothorax and tuberculosis. Thorax 1983; 38: 694-5.

6. Singh S, Girod J P, Ghobrial M W. Chylothorax as a complication of tuberculosis in the setting of the human immunodeficiency virus infection. Arch Intern Med 2001; 16: 1031-3.

7. Deniel F, Rabbat A, Laaban J-P. Chylothorax spontané bilatéral revelateur d'une tuberculose disséminée, compliquée d'une embolie pulmonaire massive. Rev Mal Respir 1999; 16: 836-8.
8. Haro M, Ruiz-Manzano J, Gallego M, Abad J, Manterola JM, Morero J. Tuberculosis pleural: análisis de 105 casos. Enferm Infecc Microbiol Clin 1996; 14: 285-89.

9. Meng F. Tan, S. H. Chan, Wan C. Tan. Comparative usefulness of PCR in the detection of Mycobacterium tuberculosis in different clinical specimens. Molecular Diagnosis 1997; 46: 164-69.

10. Schluger N W, Kinney D, Harkin T J, Rom W N. Clinical utility of the polymerase chain reaction in the diagnosis of infections due to Mycobacterium tuberculosis. Chest 1994; 105: 1116-21.

11. Nagesh BS, Sehgal S, Jindal SK, Arora SK. Evaluation of polymerase chain reaction for detection of Mycobacterium tuberculosis in pleural fluid. Chest 2001; 119: 1737-41

12. García-Zamalloa A, Ruiz-Irastorza G, Aguayo FJ, Gurrutxaga N. Pseudochylothorax. Medicine 1999; 78: 200-7.

13. Johnstone D W, Feins R H. Chylothorax. Chest Surg Clin N Am 1994; 4: 617-27. 